\title{
The system of development of the methodological-mathematical competence within future mathematics teachers to be (theoretical-methodological aspect)
}

\author{
Marina Ovchinnikova ${ }^{1 *}$,Elena Linnik $^{1}$, and Lyubov Shilova ${ }^{1}$ \\ ${ }^{1}$ V.I. Vernadsky Crimean Federal University, Simferopol, Russia
}

\begin{abstract}
The strategic guidelines in determining the theoretical and methodological principles of the system for the development of the methodological and mathematical competence of future Mathematics teachers is the implementation of the personality-oriented paradigm of education; creation of conditions for subject-subject interaction of participants in the pedagogical process; compliance with the provisions of the systemic, personality-active, integration-technological and competence approaches, the optimal combination of traditions and trends in the development of methods of mathematical education within the modeling of the content, forms and methods of organizing of the educational process. The main principles are highlighted - feasibility, integration, functional completeness, continuity, professional and pedagogical orientation, on which the pedagogical conditions for ensuring the effectiveness of the development of methodological and mathematical competence of a future teacher of mathematics are based. The use of the listed theoretical foundations in the professional training of future mathematics teachers has confirmed the effectiveness of the developed model.
\end{abstract}

\section{Introduction}

The paradigm of student-centered learning is being introduced at all educational levels in the Russian Federation. The basis for this is the following trends in the development of the national education: 1) each educational level of education has become an organic component of the system of continuous education; 2) there is a transition from a strictly regulated organization of training to forms that provide a high level of development of educational independence of students, the ability to self-education and self-realization (variability, modularity, context); 3) the educational interaction of the teacher with the students takes on the character of cooperation; 4) the transition to a holistic, system-integrated education requires the individual to be responsible for the process and the result of education. The

\footnotetext{
Corresponding author: m_ovchinnikova@ukr.net
} 
multistage system of mathematical education in the Russian Federation is one of the most important subsystems of modern education, the tendency of humanization and humanitarianization is added to the tendencies of its development.

\section{Methods}

Our research focuses on the professional training of a Mathematics teacher. The concept of the development of Mathematics education in the Russian Federation declares the need to improve the quality of the work of a mathematics teacher. In order to do so, it is necessary to provide every Mathematics teacher with the opportunity to refer to the best examples of domestic and world Mathematics education, experiences, the achievements of pedagogical science and modern educational technologies. The creation and use of your own pedagogical approaches and copyright programs become a necessary condition to become not just a teacher but a creative teacher of Mathematics [1].

Mathematical education in Russia is characterized by significant changes in the goals, content and methods of organizing the activities of schoolchildren and university students. Methodological systems and programs for teaching Mathematics are focused on developing the thinking and reasoning of schoolchildren, mastering general methods of action, using research methods of teaching and variable learning problems. These changes impose new requirements for the training of such a Mathematics teacher who is able to understand and independently implement the main ideas of competence-based teaching of Mathematics.

The structure of all modern Federal Educational Standards is based on the competence model of education. Therefore, modern pedagogical research is associated with the use of the competence approach in one way or another. This is especially true for the training of teachers and instructors of various specialties, on whose shoulders its implementation lies.

The effectiveness and consistency of the application of the competence-based approach in the conditions of the university is analyzed in the works of A. Zhafyarov [2].

The works of A. Donina [3], M. Evens [4], O. Pankratova [5], Z. Smirnova [6], S. Wang [7], are devoted to various aspects of the professional training of teachers of various specialties.

Scientists consider teacher training at different levels: secondary vocational education, Bachelor's and Master's Degrees. Even's study examines the structuring of pedagogical knowledge for students at every level of education.

S. Pozdeeva proposes a change in training models in a pedagogical magistracy, a purposeful application of a personality-oriented approach, a change in the role of a teacher as a model of pedagogical activity [8]. .

Modern teaching technologies in higher education are a constant subject for research. Much attention is paid to using the capabilities of technologies based on the use of e-learning (G. Zamaletdinova [9], N. Gluzman [10], V. Taran [11], S. Wang [7]).

$\mathrm{N}$. Yaroslavtsev's research examines the use of cognitive learning technology in a university settings. For high-quality training, the authors propose the development of competencies of specialists using specially structured knowledge [12].

The researchers also consider the features of the professional activity of a university teacher and training for it (S .Pozdeeva) [13].

N. Shestak notes that "The old stereotypes and attitudes which have been formed for centuries and have already lost their value, but continue to dictate forms, means and methods of educational process organization are a hindrance to the development of higher education." $[14$, p. 44]. And she offers an interesting approach to the phenomenon of lectures in the modern reality of the high education. The use of a competence-based approach affects the lectures, which are becoming more and more intense. 
The phenomenon of the first lecture on didactics for students of Physics and Mathematical specialties is described in the article by Y. Lukin [15]. Such a lecture makes future teachers not only evaluate their attitude to their studies, but also becomes a model for their future professional activities.

The competence-based approach in the study of mathematical disciplines together with active teaching methods becomes the subject of study (E. Guseva) [16]. Research is also devoted to the professional training of the future teacher of Mathematics (P. Gorev [17], D. Gorev [18], F. Lauermann [19], I. Pokornaya [20], E. Chernysheva [21], E. Smirnov [22]).

The analyzed resources do not exhaust the whole variety of publications devoted to the professional training of a teacher. In this article, we will share the results of our own research.

\section{Results}

The conceptual structural and functional model of the system for the development of the methodological and mathematical competence of future Mathematics teachers consists of four blocks: theoretical and methodological, design and technological, formative and effective and evaluating. This article is devoted to the description of the theoretical and methodological block of this model and the description of the primary results of its implementation in the educational process.

The fundamental theoretical and methodological principle of the concept under consideration is the choice of the key educational paradigm. The personality-oriented teaching paradigm is basic in substantiating the concept of developing methodological and mathematical competence of future mathematics teachers.

The structure of a system for the development of the methodological and mathematical competence of future Mathematics teachers in our university is carried out in accordance with the main stages of professionalization (E. Zeer [23]). At the initial stage, which consists of two parts (adaptive-orientational and information-analytical), cognitively oriented teaching is mainly used, which ensures the fundamental nature of mathematical training. At the main stage (superstructure and generalizing-systematizing) - activity-oriented training, at the final (integrative-stabilizing) - personality-oriented training. At the same time, the structure of teaching all disciplines at all stages is carried out based on the principles of a methodological orientation. The peculiarity of the last stage of training is that, in addition to the specialty of a teacher of Mathematics, graduates also receive a master's degree at the same time, that is, they additionally prepare for scientific, pedagogical and research work in higher educational institutions and scientific institutions.

The development of a concept for the development of methodological and mathematical competence is based on the following methodological approaches: synergetic, personalityactivity, competence-based and integration-technological.

The synergistic approach is aimed at identifying the interactions and interpenetration of parts of the hierarchy of structural components of an integral system of the process of training a mathematics teacher (E. Smirnov [24]).

The personal-activity approach determines the most important methodological guidelines for organizing the didactic and methodological support of the educational process of methodological and mathematical training as a system, and is focused on the subject-subject interaction based on the development and self-development of subjects of educational activity $[19,24]$.

The competence-based approach to the training of future mathematics teachers at the university is the acquisition and development of a set of key, industry-wide and subjectmethodological competencies among students, which determine their successful adaptation in professional activity. 
The integration approach is aimed at identifying and analyzing of all the integration components: basic principles, trends, roles, characteristics, properties, functions and shows the possibilities of using them as catalysts for the effectiveness of the educational process. The implementation of integrated learning contributes to the development of students' ability to perceive and assimilate mathematical and methodological knowledge as a single interconnected whole $[4,25,26]$.

The technological approach is "a tool for the systemic transformation of the existing process of training future Mathematics teachers, which acts as an important resource for increasing its effectiveness" [27, p. 103-104].

The foregoing made it possible to formulate the main conceptual provisions of the system for the development of methodological and mathematical competence of future mathematics teachers.

1. Personal and professional growth of mathematics teachers is considered as the central goal of the experimental study. In this case, the subject-subject interaction of the participants in the educational process predetermines the activity of learning and the student's selfdevelopment.

2. The system for the development of methodological and mathematical competence of mathematics teachers is based on the fusion of systemic, personality-activity, competencebased, integration-technological approaches. It is based on the following principles: expediency (correspondence of the content of training to the goals of professional and pedagogical training of a mathematics teacher, achieving a high level of his methodological training); integration (the unity of the content of teaching mathematics at different levels and the content of continuous professional training of the future mathematics teacher); functional completeness (the presence of a functionally complete set of subsystems of the system under study); consistency (continuity of studying different sections of methodological and mathematical courses); professional and pedagogical orientation (fundamentalism, binarity, continuity); personal orientation (the formation of methodological and mathematical competence through the content of training, individualization and differentiation of the educational process).

3. The system for the development of methodological and mathematical competence includes goals and objectives, a semantic resource, technological support, organizational forms, an effective component that allow students to form professional competence.

4. The functions of the system for the development of methodological and mathematical competence are in its focus on students' mastering of methodological competence, which is characterized by: personal and value attitude to the competence-based model of teaching mathematics at school; possession of a system of theoretical knowledge about the goals, content, methods, means and research principles of the development of the mathematical competence of schoolchildren; the ability to design and conduct competence-based mathematics lessons at school; the focus of their activities on reflection, self-development and self-improvement.

5. Compliance with the system of development of methodological and mathematical competence of future teachers of Mathematics with the modern level of development of professional pedagogical education, the requirements of a personality-oriented paradigm is ensured by: widespread use of forms and methods of contextual learning that contribute to mastering professional and pedagogical activities; modeling professional and pedagogical activities in the process of training Mathematics teachers by designing and solving methodological and mathematical problems and mastering the content of the integrated course "Application of the competence-based approach at different stages of Mathematical education", which ensures the transformation of students' educational work methods into quasi-professional skills and meta-professional qualities [23]; the inclusion of students in professionally-oriented competence-oriented activities, which allows transferring the 
professional pedagogical knowledge, skills, methods of activity acquired in methodological training, to the pedagogical reality of mathematical education; the content of training is determined by the level of development of modern pedagogical technologies and corresponds to future professional activities; the advanced nature of training, which is ensured by the formation of methodological and mathematical competence and the development of professional pedagogical qualities of a mathematics teacher in the process of educational, quasi-professional and educational-professional activities.

6. Organization of the development of methodological and mathematical competence of future mathematics teachers is possible in the process of creative cooperation of teachers and students. What is fundamentally important is that the provision of a student-centered learning creates conditions for the full development of all subjects of the educational process.

7. The parameters of their personal and professional development are used as criteria for the effectiveness of the development of the methodological and mathematical competence of future mathematics teachers. The assessment of these parameters is possible in the process of monitoring the professional development of the personality of the future teacher. This requires a scientifically based toolkit for determining the quality of their professional training.

International and domestic practice has shown that for the effective operation of higher education, it is necessary to create a quality control system based on traditions, experience, as well as the results of scientific research.

To control the process of training university graduates and implement a competencybased model for the development of methodological and mathematical competence of a future teacher of mathematics, tools and appropriate scales are needed to measure competence. Competency assessment makes sense for graduate courses. At the same time, the portfolio, which also includes the "methodical piggy bank", is created from the first year of study.

The cognitive and activity components of the graduate's readiness are subject to assessment, which analyze competencies and their application in a specific situation. This path provides for the following indicators of competence: student portfolio; application of practice-oriented tasks in the educational process; compulsory public defense of term papers, bachelor's, theses; introduction into practice of intermediate control, complex exams; inclusion in the final state exam of integrated tasks of a professional orientation; increasing the number of workshops that allow students to demonstrate their competencies; development of competency tests; use of case meters [10].

\section{Discussion}

The faculty of the Department of Mathematics, Theory and Methods of Teaching Mathematics is working on an initiative scientific research on the topic "Integration of educational and research activities of future mathematics teachers in the context of their personality-oriented professional training" (R\&D registration number AAAA-A18118041190060-7 from 11.04.2018). This study is a continuation of the development of proactive research work on the topic "Theoretical and methodological foundations of personality-oriented training of mathematics teachers" (R\&D registration number 115121550015 from 15.12 .2015$)$.

In the process of conducting the theoretical part of the study, we identified three main components of the professionalism system of the future Mathematics teacher: motivational, cognitive, and affective. The system for the development of methodological and mathematical competence is part of the system of professional and pedagogical training of the future teacher of mathematics. And professionalism is the result and purpose of this 
training. In the study of methodological and mathematical competence, we also relied on the listed components.

The effectiveness of the developed methodology for the stage-by-stage development of the methodological and mathematical competence of future mathematics teachers in the process of the created multi-stage training system was tested in the course of a specially organized laboratory-type control experiment. Its tasks were as follows: 1) identifying the initial levels of formation of the foundations of the methodological and mathematical competence of students through the selection and use of adequate research tools; determining the effectiveness of the developed content and technological support of the pedagogical system for the development of methodical and mathematical competence, psychological and pedagogical conditions and the main directions of its implementation based on identifying changes in indicators and levels of its formation in accordance with the proposed criteria and parameters.

The base for the experiment was the V.I. Vernadsky Crimean Federal University. The experimental sample consisted of 96 students of 8 academic groups of the first, fourth, sixth years of the training specializing in "Pedagogical Education" (Mathematics). The formation of the sample population was carried out using the method of combined selection from the general population in compliance with the requirements for the adequacy of reflection of its qualitative composition, randomization (randomness), statistical significance (additional processing of the results of the sample experiment using the methods of mathematical statistics and testing statistical hypotheses, taking into account the errors of representativeness).

In the selection of experimental groups, we were guided by the standard approach of scientific and pedagogical research, according to which the thesis was formulated that the use of control groups in a pedagogical experiment is not always justified, since it is practically unattainable to compare students who are parallel in their knowledge, development, and upbringing. You can check the equality of the starting conditions in terms of knowledge (test work), but not in terms of the levels of formation of their motivational, intellectual, subjectpractical, regulatory, volitional spheres. Comparing existential spheres and individuality is generally an impossible task. Therefore, the object can be studied in development, and the recording and comparison of changes in its indicators and parameters can be carried out before and after the experimental impact. In accordance with this, three experimental groups of students were formed, under the direct guidance of the teachers of the department they mastered the disciplines of the curriculum. G1 - 45 first year students, G2 - 25 third year students; G3 - 26 sixth year undergraduates.

Table 1. The levels of formation of the motivational component of the methodological and mathematical competence of students.

\begin{tabular}{|c|c|c|c|c|}
\hline \multirow{2}{*}{ Levels } & High & Medium & Low \\
\cline { 2 - 5 } & Groups & $\mathbf{\%}$ & $\mathbf{\%}$ & $\mathbf{\%}$ \\
\hline \multirow{3}{*}{ G1 } & Up to & 6,4 & 34 & 59,6 \\
\cline { 2 - 5 } & After & 10,7 & 63,8 & 25,5 \\
\cline { 2 - 5 } & Changes & 4,3 & 29,8 & $-34,1$ \\
\hline \multirow{3}{*}{ G2 } & Up to & 12 & 46 & 42 \\
\cline { 2 - 5 } & After & 14 & 50 & 36 \\
\cline { 2 - 5 } & Changes & 2 & 4 & -6 \\
\hline \multirow{3}{*}{ G3 } & Up to & 24,5 & 60,4 & 15,1 \\
\cline { 2 - 5 } & After & 28,3 & 58,5 & $-1,9$ \\
\cline { 2 - 5 } & Changes & 3,8 & 1,9 & \\
\hline
\end{tabular}

In the course of multi-stage experimental work, we performed diagnostic sections of the research. The determination of the effectiveness of the experimental work was carried out on 
the basis of the analysis of changes in the development of the corresponding areas of professional and pedagogical growth of students. Let's characterize the dynamics of their development.

The results (table 1) show a significant reduction in the number of low-level students due to an increase in the average level (especially in G1 by more than 34\%). Slightly lower intensity of changes in motivation was observed among students G2 and G3, although a gradual increase under the influence of experimental teaching in the number of middle-level students at the first stage of methodological and mathematical training can be considered positive. In G2 from $46 \%$ to $50 \%$ and a high level among G3 master's students from $24 \%$ to $28.3 \%$. This is due, in our opinion, to the relative stabilization of the system of methodological and mathematical views, ideals, tastes in the senior years and in the magistracy under the influence of various professionally oriented academic disciplines and pedagogical practice. Freshmen have a predominantly spontaneous-romantic character of motivation. At the same time, in the individual indicators of the motivational component of the methodological and mathematical competence of some students G2 and G3, isolated cases of negative dynamics were observed. This can be explained by a certain reorientation of their professional motives and interests as a result of a deeper understanding of the peculiarities of the profession of a Mathematics teacher and reflection of their own capabilities and aspirations. Among the Master students in the control group, the average level of formation of professional motivation (53.7\%) prevails, with a very small number of high-level students (only 7.3\%) and a significant number of low-level students (39\%).

Table 2. The levels of formation of the cognitive component of the methodological and mathematical competence of students.

\begin{tabular}{|c|c|c|c|c|}
\hline \multirow{2}{*}{ Levels } & High & Medium & Low \\
\cline { 2 - 5 } & Groups & $\mathbf{\%}$ & $\mathbf{\%}$ & $\mathbf{\%}$ \\
\hline \multirow{3}{*}{ G1 } & Up to & 0 & 10,6 & 89,4 \\
\cline { 2 - 5 } & After & 0 & 25,5 & 74,5 \\
\cline { 2 - 5 } & Changes & 0 & 14,9 & $-14,9$ \\
\hline \multirow{3}{*}{ G2 } & Up to & 0 & 18 & 82 \\
\cline { 2 - 5 } & After & 10 & 76 & 14 \\
\cline { 2 - 5 } & Changes & 10 & 58 & -68 \\
\hline \multirow{3}{*}{ G3 } & Up to & 3,8 & 68 & 28,2 \\
\cline { 2 - 5 } & After & 41,5 & 52,8 & 5,7 \\
\cline { 2 - 5 } & Changes & 37,7 & $-15,2$ & $-22,5$ \\
\hline
\end{tabular}

The greatest development (Table 2) was achieved by the indicators of the cognitive component of the methodological and mathematical competence of the students of the experimental groups, the abrupt change of which was especially observed in G2. This is due to the fact that at this stage students received fundamental mathematical and basic methodological and mathematical training. This led to a decrease in the low level of its formation from $82 \%$ to $14 \%$ and an increase in the average from $18 \%$ to $76 \%$. There appeared about $10 \%$ of students with a high level of development of the cognitive component, who basically already had secondary vocational education and work practice at school. And they also took an active part in the work of scientific circles, problem groups, in olympiads and independently developed scientific and methodological topics. Undergraduates G3 previously had methodical and mathematical training at the Bachelor's level and were recruited mainly from students with high academic performance. Therefore, they showed the following dynamics: the transition from the middle level (68\%) to the high $(41.5 \%)$. Only $5.7 \%$ remained at a low level. Significantly less intensive dynamics of the development of the cognitive component of pedagogical professionalism was observed in G1. First-year students received only primary scientifically grounded ideas about the methods of teaching 
Mathematics. This made it possible to reduce the percentage of low-level students and, accordingly, increase the average by $14.9 \%$. This fact also explains the absence in G1 of students of a high level of formation of this component.

Table 3. The levels of formation of the affective component of the methodological and mathematical competence of students.

\begin{tabular}{|c|c|c|c|c|}
\hline \multirow{2}{*}{ Levels } & High & Medium & Low \\
\cline { 2 - 5 } & Groups & $\mathbf{\%}$ & $\mathbf{\%}$ & $\mathbf{\%}$ \\
\hline \multirow{3}{*}{ G1 } & Up to & 6,4 & 51,1 & 42,5 \\
\cline { 2 - 5 } & After & 4,3 & 70,2 & 25,5 \\
\cline { 2 - 5 } & Changes & $-2,1$ & 19,1 & 17 \\
\hline \multirow{3}{*}{ G2 } & Up to & 4 & 50 & 46 \\
\cline { 2 - 5 } & After & 10 & 76 & 14 \\
\cline { 2 - 5 } & Changes & 6 & 26 & -32 \\
\hline \multirow{3}{*}{ G3 } & Up to & 22,6 & 56,6 & 20,8 \\
\cline { 2 - 5 } & After & 26,4 & 64,2 & 9,4 \\
\cline { 2 - 5 } & Changes & 3,8 & 7,6 & $-11,4$ \\
\hline
\end{tabular}

Control measurements of the formation of the affective component (table 3) showed the complexity and indirect nature of the pedagogical management of the development of the emotional sphere of the methodological and mathematical competence of future mathematics teachers due to its extremely delicate psychological organization. It is this fact that explains the negative dynamics of this component. This led to a decrease in the number of high-level students in the affective component in G1 by $2.1 \%$, and in G2 and G3 such students increased only by $6 \%$ and $3.8 \%$. An explanation of this fact can be the acquisition by students in the learning process of the experience of professional emotional-volitional self-regulation, rationalization of the statement and correction of their own emotional reactions and experiences, and it is quite possible with experimental sections to situational states of frustration, emotional indifference, lack of creative upsurge, and the like.

\section{Conclusion}

The results show the effectiveness of the applied methodological system for the development of the methodological and mathematical competence of future Mathematics teachers at a pedagogical university. In further research it is planned to isolate and consider the conative component of the system under consideration.

Thus, the construction of the concept of the development of the methodological and mathematical competence of future Mathematics teachers creates opportunities for the development and application of the theory, methodology and technology of its practical implementation in a pedagogical university. The new quality of the methodological and mathematical training of future Mathematics teachers in close connection with the radical improvement of its use is one of the main problems of the modern system of mathematical education.

\section{References}

1. The Concept of Development of Mathematical Education in the Russian Federation (Moskow, 2013)

2. A. Zhafyarov, Competence approach: Consistent theory and technology, Science for Education Today, 9 (2), 81-95 (2019) 
3. I. Donina, E. Vezetiu, Teacher's readiness for marketing activities as a condition of quality education, The European Proceedings of Social and Behavioural Sciences, 59, 933-940 (2019)

4. Marie Evens, Jan Elen, Charlotte Larmuseau, Depaere Fien, Promoting the development of teacher professional knowledge: Integrating content and pedagogy in teacher education, Teaching and Teacher Education, 75, 244-258 (2018)

5. O. Pankratova, E. Konopko, R. Nemkov, O. Mezentseva, The preparation of a modern Computer Science teacher with the help of resource-saving technologies and Green IT implementation, Integrating Research Agendas and Devising Joint Challenges International Multidisciplinary Symposium ICT Research in Russian Federation and Europe, 222-228 (2018)

6. Z. Smirnova, N. Kamenez, O. Vaganova, L. Kutepova, E. Vezetiu, The experience of using the webinar in the preparation of engineering specialists, Amazonia Investiga, 8 (18), 279-287 (2019)

7. S. Wang, N. Gorbunova, A. Masalimova, J. Bírová, M. Sergeeva, Formation of academic mobility of future foreign language teachers by means of media education technologies, Eurasia Journal of Mathematics, Science and Technology Education, 14 (3), 959-976 (2018)

8. S. Pozdeeva, Master's degree environment as a space for personal professional development of students and professors, Higher education in Russia, 3 (210), 144-152 (2018)

9. G. Zamaletdinova, N. Konopleva, N. Gluzman, N. Gorbunova, Development of electronic educational resources for studying mathematics by adobe flash and html5 systems at elementary schools, The Journal of Social Sciences Research, S1, 171-174 (2018)

10. N. Gluzman, T. Sibgatullina, A. GalushkinA., I. Sharonov, Forming the Basics of Future Mathematics Teachers' Professionalism by Means of Multimedia Technologies, EURASIA Journal of Mathematics, Science and Technology Education, 14 (5), 1-13 (2018)

11. V. Taran, Use of Elements of Augmented Reality in the Educational Process in Higher Educational Institutions, CEUR Workshop Proceedings. In 2019 International Conference on Innovative approaches to the application of digital technologies in education and research SLET-2019 (2019)

12. N. Yaroslavtseva, A. Belyakov, B. Tukhvatullin, A. Kodoeva, V. Nigamatulin, D. Levchenko, A. Dakhin, Cognitive learning technology: essence, efficiency and effectiveness, Perspectives of Science and Education, 43 (1), 10-23 (2020)

13. S. Pozdeeva, University teacher: methodologist, reseacher, novator?, Higher education in Russia, 3 (210), 52-58 (2017)

14. N. Shestak, Lecture in post-secondary education institution within the context of competence approach, Higher education in Russia, 8-9 (27), 43-53 (2018)

15. Y. Lukin, "Which of you is ready to take a leap to the emptiness today"?, Higher education in Russia, 8-9 (27), 54-61 (2018)

16. E. Gusakova, T.Gusakova, Active methods in teaching mathematics in high school, Perspectives of Science and Education, 1 (31), 33-38 (2018)

17. P. Gorev, A. Kalimullin, Structure and Maintenance of a Mathematical Creative Lesson as a Mean of Pupils' Meta-Subject Results Achievement, EURASIA Journal of Mathematics, Science and Technology Education, 13 (6), 2701-2720 (2017) 
18. D. Gorev, I. Gurevich-Leibman, Experience of Integrating Various Technological Tools into the Study and Future Teaching of Mathematics to Education Students, International Journal of Mathematical Education in Science and Technology, 46 (5) 737-752 (2015)

19. F. Lauermann, J. König, Teachers' professional competence and wellbeing: Understanding the links between general pedagogical knowledge, self-efficacy and burnout, Learning and Instruction, 45, 9-19 (2016)

20. I. Pokornaya, S. Titorenko, A. Ovsiannikova, Some issues of improving the training of masters of the field 44.04.01 Pedagogical education under the program "Math education", Perspectives of Science and Education, 3 (39), 184-195 (2019)

21. E. Chernysheva, E. Kubryakov, The experience of practice-oriented training model implementation for teacher-training education university students, specialising in physics and mathematics, Perspectives of Science and Education, 5 (35), 65-73 (2018)

22. E. Smirnov, T. Zykova, S. Tikhomirov, The management of school mathematical education with synergistic effect, Perspectives of Science and Education, 2 (38), 190202 (2019)

23. E. Zeer, A. Pavlova, E. Symaniuk, Modernization of professional education: a competence-based approach, p. 216 (Moscow, 2005)

24. E. Smirnov, S. Tikhomirov, S. Dvoryatkina, Self-organization technology of student's mathematical activities based on intelligent management, Perspectives of Science and Education, 3 (45), 77-86 (2020)

25. V. Proshkin, Integration of research and educational work in university training of future teachers: theory and practice, p. 456 (Monograph, Luhansk: Publishing House of Taras Shevchenko LNU, 2013)

26. Y. Lukin, The essence of pedagogical integration, Perspectives of Science and Education, 2 (38), 68-83 (2019)

27. L. Koval, Professional training of future primary school teachers: technological component, p. 375 (Monograph, Donetsk: Yugo-Vostok, 2009) 